\title{
EL CULTIVO DEL ARROZ DE SECANO \\ EN CATALUÑA (1778-1839). UNA PROPUESTA \\ AGRONÓMICA AL PROBLEMA DEL PALUDISMO
}

\section{Andrés Sobrevía Clavera}

IES Torre Vicens, Lleida

\section{RESUMEN}

El objetivo del presente artículo es analizar el programa sanitario desplegado en Cataluña para erradicar el paludismo utilizando el cultivo del arroz de secano. Siguiendo una concepción miasmática de la enfermedad, las fiebres palúdicas se vinculaban a los humedales arroceros y eliminándolos se erradicaba el foco de una enfermedad desconocida en su origen y transmisión.

PALABRAS CLAVE: Agronomía, arroz, Cataluña, paludismo, Valencia.

\section{SUMMARY}

This article analyzes the sanitary program unfolded in Catalonia, in order to eradicate paludism, by means of growing rice without floods. Since fevers were attributed to rice plantations, the elimination of this practice implied a miasmatic interpretation of the disease. This interpretation had some agronomic repercussions, which were assumed as the solution for a disease whose origin and transmission were unknown.

KEY WORDS: Agronomy, Cataluña, paludism, rice, Valencia.

\section{INTRODUCCIÓN}

A finales del siglo XVIII y durante gran parte del siglo XIX, la medicina, la química y la agronomía confluyeron en la problemática higiénico sanitaria generada en las regiones pantanosas y donde la práctica agrícola promovía la estanqueidad de las aguas ${ }^{1}$. El paradigma miasmático reinaba en la ciencia de

1 Además del cultivo del arroz por inundación permanente, estuvieron bajo sospecha las balsas de enriar el cáñamo y el lino. El enriamiento o maceración consistía en depositar las gavillas del vegetal en charcos o balsas de agua, por un tiempo que variaba entre ocho o diez 
la época. La causa de las fiebres intermitentes, tercianas y cuartanas, se relacionaba con los miasmas, efluvios o exhalaciones, emanados de aquellos lugares a causa de la putrefacción de las aguas por contener restos orgánicos. La medicina, mediante la quina, había hallado un tratamiento eficaz, pero su empleo no podía generalizarse debido a su limitado suministro. La mayor precisión de las técnicas pneumáticas permitió que la química investigara la probable relación entre la composición atmosférica de ciertos parajes y las epidemias palúdicas. La agronomía moderna, como disciplina científica naciente, planteó una mejora de las técnicas de cultivo con el fin de eliminar el hipotético mefitismo² palúdico.

En Cataluña hubo dos tentativas para solucionar el problema. La más importante fue el conjunto de ensayos realizados con el denominado arroz de secano, en los que se sustituía el riego permanente por riegos periódicos; la segunda fue hallar un proceso diferente al enriamiento del cáñamo. Todas estas tentativas tuvieron una motivación exclusivamente sanitaria, ya que desde un principio se presumía una disminución de los rendimientos agrícolas. Las experiencias agronómicas partían de la hipótesis de que existía una clase de arroz adaptable a las condiciones del suelo y el clima del país, sin necesidad de riego permanente; el conjunto de relaciones complejas (plantasuelo-clima) sometidas a factores aleatorios hizo difícil comprenderlo, pero constituye un ejemplo temprano de cuáles debían ser los objetivos de la agronomía ${ }^{3}$. Los inicios de estas experiencias en Europa fueron posteriores a 1720, fecha considerada como punto de partida en el establecimiento de una política de la salud 4 . En nuestro país hubo voluntad de los gobernantes para que el pueblo conociera las medidas higiénicas, pues la salubridad de las ciudades fue una de sus preocupaciones.

días. En aquel estado se desarrollaba una fermentación que facilitaba la separación de las fibras por la acción de los medios mecánicos empleados después de la maceración.

2 Mefistismo se refería a un vicio de la atmósfera que la hacía irrespirable y derivaba de mofeta, término antiguo que significaba todo gas no adecuado para la respiración.

3 Cf. Sebillotte, M. (1974), «Agronomie et agriculture. Essai d'analyse des tâches de l'agronome», Cahiers du Comité technique d'Agronomie de l'ORSTOM, sér. Biol. nº 24, París, pp. 3-25.

4 URTeAgA, L. (1980), «Miseria, miasmas y microbios. Las topografías médicas y el estudio del medio ambiente en el siglo XIX», Cuadernos críticos de Geografía Humana, año V, $\mathrm{n}^{\circ} 29$, Barcelona. 


\section{ORIGEN DE LAS FIEBRES INTERMITENTES}

A finales del siglo XVIII se está aún lejos de conocer la causa del paludismo $^{5}$. Hasta 1880 no se describió el agente patógeno, un protozoo descubierto por Laveran quien supuso que los mosquitos pueden infectarse con la sangre chupada al enfermo ${ }^{6}$. Gracias a las investigaciones de Manson, Ross, Grassi, Bignami y Bastianelli (1898), se descubrió el ciclo sexual de los plasmodios en el mosquito del género Anopheles y el mecanismo de transmisión a la especie humana ${ }^{7}$. Desde tiempos remotos se relacionaban los terrenos pantanosos con el paludismo, atribuyéndose la causa a los aires pestilentes $^{8}$, sobre todo nocturnos, motivo por el cual los habitantes cercanos se consideraban a salvo si cerraban puertas y ventanas para impedir que entraran en su casa. Las poblaciones afectadas habían reunido una serie de observaciones para las que carecían de explicación: se sabía que los niños lactantes y las mujeres que permanecían más tiempo en sus casas tenían una incidencia menor de paludismo; que en sitios elevados próximos a los pantanos no se experimentaban los efectos de la enfermedad, deduciéndose que el vapor de

5 Paludismo, del latín palus, que significa laguna y que a su vez deriva del griego $p a-$ laios (viejo o antiguo) y de palos (lodo). La denominación de malaria, del italiano mal'aria (mal aire), era muy reciente, fue el botánico italiano Torti quien, en 1753, utilizó por primera vez este vocablo. En Inglaterra no se utilizó hasta 1837, y en los textos españoles que hemos consultado, anteriores a la mitad del siglo XIX, no se la nombra nunca así. La denominación más usual es la de tercianas y fiebres intermitentes.

6 Este aspecto fue demostrado por Ronald Ross en 1897.

7 La primera especie de esporozoario estudiada por Laveran fue el Plasmodium malariae causante de la fiebre cuartana, completando su ciclo en el hombre en unas 72 horas. El Plasmodium vivax fue observado por primera vez en 1880, también por Laveran, es causa del paludismo terciano o terciana benigna y el ciclo esquizogónico dura 48 horas. La tercera especie de plasmodio, es el $P$. falciparum productor del paludismo subterciano, terciano maligno, tropical o estivo-otoñal, y del que también Laveran describió sus gametocitos falciformes (las medias lunas de Laveran). El $P$. vivax es la especie dominante en las zonas templadas. El $P$. malariae tiene una zona restringida de distribución y es poco común, excepto en la parte occidental y central de Africa. El P. falciparum es la especie dominante de las regiones tropicales, y no suele encontrarse en las regiones cuya temperatura media en el verano es inferior a $21,1^{\circ} \mathrm{C}$, o la del invierno desciende de $8,8^{\circ} \mathrm{C}$; era la especie más común en el sur de Europa y norte de Africa, causando aquí una infección sintomática en el verano y comienzo del otoño, por lo que se le llamó paludismo estivo-otoñal. $C f$. CRAIG, C. F.; FAUST, E. C. (1951), Parasitología clínica, México, Unión Tipográfica Edit. Hispano Americana, pp. 193-235.

8 Lo común era considerar que los efluvios tenían su origen en la putrefacción de la materia orgánica, pero hubo opiniones que atribuían los efluvios a emanaciones especiales de ciertas plantas que crecían en las regiones pantanosas, conocidas como vegetación palúdica. 
agua era el vehículo del agente pernicioso. La interposición de un obstáculo natural, como una colina o un bosque, podía ser un buen medio para preservar a una población cercana a un foco palúdico. Con la creencia de que los efluvios no podían elevarse mucho, las personas más acomodadas escogían para su vivienda los pisos altos de las casas. Se afirmaba que el mefitismo era mucho mayor en sitios bajos, o rodeados de montañas, por su menor ventilación natural, saturándose fácilmente la atmósfera de efluvios. También se sabía que la fuerza del mefitismo palúdico guardaba relación con las temperaturas del día, de la estación anual y del país; con la dirección de los vientos, la altura del lugar y su situación geográfica. Las horas de más peligro eran la madrugada y el anochecer, circunstancia que incidía en la creencia de que el vapor acuoso servía de vehículo de los efluvios. Casuística que se explicaba suponiendo que en las horas de más calor desaparecía la humedad y por lo tanto el soporte de los efluvios, sin embargo el calor del medio día favorecía la putrefacción de las aguas, por ello al atardecer y aumentar la humedad el mefitismo era muy intenso. La estación del año más temida era el otoño, puesto que los pantanos contenían menos agua y abundaban los restos vegetales al terminar las plantas anuales su ciclo. Respecto a los países más susceptibles de padecer el paludismo se consideraba que eran los más cercanos al Ecuador, por su mayor temperatura media anual y el crecimiento más vigoroso de la vegetación.

Los griegos identificaron el miasma palúdico con seres monstruosos. Hipócrates estudió la enfermedad en Asia menor, donde en el siglo V antes de Cristo ya predominaba. Tanto Hipócrates como los médicos griegos reconocían en el aire las causas de las enfermedades. Los tratados hipocráticos indicaban la importancia que para la enfermedad tenía la calidad del aire, subrayando diferentes aspectos: la situación de los lugares, las cualidades del suelo, sus diferentes exposiciones y la variedad de sustancias que encierra. La tradición hipocrática dio lugar a la creencia de que las fiebres ${ }^{9}$ tenían su origen en las exhalaciones generadas en las aguas estancadas siendo generalmente admitido por los autores del siglo XVIII, como Sigaud de la Fond en su ensayo sobre los diferentes tipos de air-fixe $e^{10}$.

9 No sólo se pensaba que las emanaciones nocivas generaban fiebres intermitentes, también la fiebre amarilla, el cólera y la peste bubónica se daban en condiciones análogas al paludismo. Gracias a que la quina actuaba específicamente contra el paludismo pudo separárselo de otros procesos febriles diferentes.

10 DE LA FOND, S. (1785), Essai sur différents especes d'air-fixe ou de gas, pour servir de suite et de supplément aux Elémens de Physique du même Auteur, París, Chez P. Fr. Gueffier, p. 410. 
En el siglo II a.C., el romano Marco Terencio Varrón aconsejaba evitar los pantanos «porque se crían ciertas criaturas diminutas que no se pueden distinguir a simple vista, que vuelan por los aires y entran al cuerpo por la boca y la nariz, y que pueden causar graves enfermedades $\rangle^{11}$. Frente a la teoría de los miasmas, la afirmación de Varrón apunta a un origen microbiano de la enfermedad. Paladio y Vitruvio sostuvieron esta idea, y el jesuíta alemán Atanasius Kircher la defendió alcanzado el siglo XVII ${ }^{12}$. Paracelso y su escuela atribuyeron la insalubridad de los sitios pantanosos a la conjunción de los astros, en especial a las posiciones de Saturno. Los humoristas consideraron la putrefacción de la sangre ocasionada por el calor y la humedad. Federico Hoffman, por ejemplo, creía que el aire saturado de vapor perdía su elasticidad y, por lo tanto, la propiedad de comunicar fuerza expansiva a la sangre, languideciendo la circulación y acumulándose humores impuros.

En la literatura de la época, y no sólo en la higiénico sanitaria, son numerosas las referencias a una explicación miasmática, telúrica o atmosférica de las enfermedades. El viajero irlandés Guillermo Bowles explicaba la escasa incidencia de tercianas en el norte de España por la presencia de corrientes de aire, capaces de arrastrar consigo los efluvios pestilentes ${ }^{13}$. En su Tratado de Calenturas, publicado en Valencia en 1751 y traducido al francés en 1768, Andrés Piquer y Arrufat concluye que los síntomas de las calenturas epidémicas variaban según los años, imputando estas diferencias al estado de la atmósfera. Según el catedrático de anatomía de la universidad de Valencia la enfermedad relacionaba los diferentes agentes que alteraban el aire variando sus modos y manera: «Yo congeturo que nacen principalmente de la Atmosfera, como esta sea diversa cada año, y puedan todas las causas que concurren con ella combinarse de infinitas maneras, pueden variar de muchos modos estas enfermedades. Es deseable que los Médicos se apliquen a formar las historias de semejantes calenturas» ${ }^{14}$.

11 Citado por Sutcliffe, J. (1993), Historia de la Medicina, Barcelona, Blume, p. 21.

12 Cf. VidAL, F. (1880), Estudio especulativo e histórico del agente palúdico, Barcelona, Es. tip. sucesor N. Ramírez, p. 8. Un texto muy parecido al anterior, sobre el tema del paludismo, es el de Juan Giné, catedrático en la Facultad de Medicina de Barcelona, socio de la Academia de Medicina y Cirugía, y miembro de la Sociedad Económica Barcelonesa de Amigos del País. GiNÉ, J. (1882), Curso elemental de higiene privada y pública, Barcelona, Bastinos Editores, 2 vols.

13 Bowles, G. (1782), Introducción a la Historia Natural, y a la Geografía Física de España, Madrid, p. 329.

14 PiQuer, A. (1745), Física moderna, racional y experimental, Valencia, t. I, p. 376. 
En general, hasta finales del siglo XIX se ignoraron los mosquítos al describir el paludismo ${ }^{15}$. La enfermedad se relacionaba exclusivamente con la putrefacción de la materia orgánica, tanto en el suelo como en las aguas estancadas, y la contaminación de su atmósfera adyacente ${ }^{16}$. La corrupción pasaba al aire y de allí al hombre. Hasta época avanzada, se creyó que la infección procedía del suelo y que no se transmitía de unos individuos a otros ${ }^{17}$, la teoría de los miasmas no necesitaba de otro vector que el aire, tal y como afirma Jaccoud en su Tratado de patología interna:

«El veneno de la malaria (infeccion palúdica) agota sus efectos en el individuo que le ha absorbido, no se regenera, y por lo tanto no es transmisible; los otros venenos son reproducidos por el enfermo, y de consiguiente pueden transmitirse del hombre enfermo al sano, de donde es fácil deducir que todo veneno reproductible es transmisible... La infeccion palúdica es producida por un veneno telúrico, llamado miasma palúdico ó simplemente malaria. Las formas clínicas del envenenamiento palúdico son múltiples; se manifiesta por fiebres intermitentes, normales o anormales, por fiebres remitentes, por una caquexia especial. La fiebre intermitente es la forma mas comun» ${ }^{18}$.

Se ignoraba la verdadera causa de la enfermedad, pero nadie dudaba de que su origen estaba en la descomposición de la materia orgánica en las aguas estancadas. Sobre este hecho había observaciones que relacionaban el descenso de los afectados con una disminución de la temperatura del ambiente, con una desecación de las zonas pantanosas, o un alejamiento de esas zonas, y una

15 Los mosquitos no eran más que un signo, un símbolo de la insalubridad del aire. La mayor cantidad de mosquitos se daba en los lugares malsanos. En su viaje por las selvas del Orinoco, Alexander von Humboldt (1769-1859) topó con la pesadilla de los mosquitos y creyó que también contribuían a la insalubridad. Pero su visión fue completamente miasmática, pensaba que la gran cantidad de larvas y mosquitos llenos de veneno que se pudrían en las aguas difundían miasmas a la atmósfera; además las molestas picaduras disponían a que el cuerpo fuera afectado por los miasmas.

16 La idea de que el aire desprendido de los cuerpos conserva los vestigios de su lugar de procedencia se halla en una memoria de Chaussier leída en la Academia de Dijon, el 17 de agosto de 1777. La materia en putrefacción generaría una atmósfera con características semejantes y, por lo tanto, indeseables. $C f$. DE LA FOND (1785), p. 11.

17 Girolamo Fracastoro, considerado el padre de la epidemiología moderna y el primero que estableció con claridad el concepto de enfermedad contagiosa, no incluyó al paludismo entre las enfermedades contagiosas, descritas en su libro De contagione et contagiosis morbis et eorum curatione (1546).

18 Jaccoud, S. (1876), Tratado de Patología interna, Madrid, t. II, Carlos BaillyBailliere, pp. 612-613. 
atenuación de los efectos cuando soplaban fuertes vientos. Lo cual tenía fácil explicación desde la teoría de los miasmas, y permitía establecer, como se ha dicho, que las barreras físicas establecidas por los bosques, las montañas, $\mathrm{y}$ los edificios, podían detener el avance de la epidemia.

\section{REMEDIOS CONTRA LAS FIEBRES INTERMITENTES}

Finalizando el siglo XVIII los estudios de la química pneumática habían demostrado las propiedades del aire vital u oxígeno, y la salubridad del aire atmosférico se relacionó con su proporción. Defendiendo esta premisa, Pedro Gutiérrez Bueno, en su Prontuario de química, respondía la pregunta ¿qué aire atmosférico es más puro?, afirmando: «El que mejor contribuya á la salubridad, ó que tenga mas oxigeno» ${ }^{19}$. Similar principio guiaba la desecación y puesta en cultivo de terrenos pantanosos, interpretándose como una prueba de la infección del aire y del poder que tenían los vegetales para volverlos salubres aumentando el porcentaje de oxígeno. Sigaud de la Fond citaba como ejemplo a los primeros colonos de Jamaica, quienes, antes de desecar y cultivar los pantanos, tenían una supervivencia inferior a diez años, y posteriormente vivían casi tanto como en Europa. La demostración de la producción de oxígeno por los vegetales promovió la plantación de árboles de crecimiento rápido, como el plátano y el chopo lombardo ${ }^{20}$, en los alrededores de los terrenos pantanosos, las inmediaciones de los cementerios y el entorno de los hospitales para oxigenar el ambiente. El eucalipto fue otro árbol utilizado en la cruzada miásmica, por las propiedades balsámicas de sus hojas y su gran capacidad para desecar el suelo ${ }^{21}$.

19 Gutiérrez Bueno, P. (1815), Prontuario de química, farmacia y materia médica, Madrid, Imp. de Villalpando, p. 34.

20 Hacia el año 1650, del cruce entre Platanus occidentalis y Platanus orientalis, se obtuvo un híbrido al que se ha llamado plátano híbrido español y también plátano de Londres $(P$. $\mathrm{x}$ hispanica). Este árbol presenta un vigor excepcional y se ha convertido en el árbol de las calles en Europa y América. En la generalización de su plantación intervino la sugerencia de Sigaud de la Fond. El chopo lombardo, también aconsejado por Sigaud, es la variedad Italica del Populus nigra.

21 Para sanear el valle de Méjico por disminución del exceso de humedad, en 1882 el Dr. De Bellina consideró necesario plantar 52.650.000 eucaliptos; además la inhalación de los efluvios balsámicos debía neutralizar los efectos nocivos sobre la circulación sanguínea de los olores fétidos. «Memoria del Dr. De Bellina sobre la enfermedad del paludismo en México», Gaceta Médica de México, t. 17, 1882, pp. 347-413. 
También se tomaron medidas urbanísticas para evitar que el aire se impregnara de miasmas, como situar los cementerios en las afueras de los pueblos y prohibir los enterramientos en las iglesias. Una real orden de 1775 abolía en España los cementerios de las iglesias parroquiales con el propósito de transformarlos en plazas, pero aún existían algunos durante el siglo XIX. La Academia Médico-Práctica de Barcelona consideró perniciosos para la salud pública los cementerios de las iglesias y los olores y humos provinientes de las fábricas, atribuyéndoles la causa de muchas muertes súbitas y ataques de apoplejía ${ }^{22}$. Se promovió también la plantación de arbolado en esos lugares, para que los productos de la descomposición fueran absorbidos por las hojas. Las publicaciones periódicas iban aportando noticias del constante traslado de los cementerios hacia las afueras de las poblaciones. La justificación era el peligro de las fiebres y el deseo de disponer de un aire más puro.

Una técnica destacable para eliminar los efluvios perniciosos, o al menos agitar artificialmente el aire, fue el uso de ventiladores. Su inventor fue Stephen Hales y pretendía eliminar el aire fétido de prisiones, hospitales, minas, barcos y lugares cerrados. Aunque se dudaba de que la agitación artificial eliminara los miasmas, al menos los difundía en un mayor volumen atmosférico y, así, perdían sus propiedades nocivas. En la búsqueda de soluciones hay que destacar el cambio de actitud de parte del clero para la erradicación de las epidemias. Ahora, junto a las oraciones se buscaron y aplicaron remedios terrenales. Es el caso de Jaime Cesat, párroco del pueblo de Valls y socio de la Real Sociedad Económica de Tarragona. Cesat mantuvo correspondencia con el hacendado y científico Antonio Martí y Franqués pidiéndole información sobre los avances técnicos aplicados para combatir el contagio. La carta está fechada el 19 de julio de 1804:

«Muy Sor. mio de todo mi aprecio: En el tomo 8 de la obra del Abate Andres Lib. 2 Cap. 2 de la Física particular, he leído lo siguiente: "Las lagrimas batavicas hicieron pasmar á los Filosofos hasta qe. pensaron reducir sus prodigios â esta elasticidad (habla de la del ayre). En beneficio de la respiracion de la salud, y de la humanidad ha deducido Desaguliers estas poderosisimas propiedades del ayre, y con el auxilio de los conocimientos fisicos sobre el mismo ha inventado los ventiladores, y otras maquinas qe. han librado de la infeccion del ayre â los hospitales, y otros lugares donde la concurrencia de muchas personas lo hacia peligroso.

22 Jaime Carrera Pujal (1951), La Barcelona del segle XVIII, Barcelona, Edit. Bosch, v. I, pp. 363-377, afirma que mientras los barceloneses se resistían a admitir que fuese un peligro para la salud la permanencia de cementerios rodeados por casas, en cambio eran muy sensibles al mal olor y al humo de las industrias, frecuentemente denunciados. 
Como no tengo presente haver leido qe. sean las lagrimas batavicas, ni tengo noticia de los ventiladores de qe. habla Andres, citando a Desaguliers: he pensado qe. V. podria instruirme de uno y otro, ó bien con las noticias qe. diere algun autor sobre el particular. Espero merecerle â V. este favor, y ocasiones de emplear en obsequio de $\mathrm{V}$. el sincero afecto con que soy....» $\rangle^{23}$.

En el arzobispo de Tarragona, Romualdo Mon y Velarde, se halla otro ejemplo de este cambio de actitud. El día cuatro de septiembre de 1804 enviaba una circular al clero de su arzobispado exhortando a la oración para aplacar la justicia divina «e implorar su clemencia, á fin de que se digne hacer cesar tan terrible azote donde hasta ahora se ha sentido, y preserve de el al Pueblo Christiano» ${ }^{24}$. Pocos meses después, el 18 de marzo de 1805 , el arzobispo confiaba menos en la gracia divina y dirigía una extensa circular a los párrocos recomendando también remedios materiales para luchar contra la epidemia ${ }^{25}$. La información procedía, probablemente, de un opúsculo en el que el catedrático del Real Colegio de Farmacia de Madrid, Pedro Gutiérrez Bueno, había descrito un aparato para desinfectar el aire, ideado por Guyton de Morveau, que el propio Gutiérrez había modificado ${ }^{26}$. Las fumigaciones propuestas por Morveau se adoptaron en toda Europa, y la circular arzobispal pretendía familiarizar a los párrocos con aquel sistema dándoles reglas precisas. La circular desaconsejaba, por ineficaces, remedios habituales como los sahumerios de plantas aromáticas e incienso, combustión de leña ${ }^{27}$ y las pulverizaciones de vinagre, medidas que sólo enmascaraban el mal pero no actuaban sobre la verdadera raíz: «Para esto no hay mas remedio que destruir los Corpúsculos que contienen el mal, aniquilar los miasmas pútridos que esparcidos por el aire atacan á los que le respiran ó participan de su contacto. Nada se hará en cortar la planta, ni aun en arrancarla, sino se destruye la se-

23 Biblioteca Hemeroteca Municipal de Tarragona (BHMT). Epistolario de Martí Franqués, $\mathrm{n}^{\mathrm{o}} 372$.

24 Archivo Histórico Archidiocesano de Tarragona (AHAT). Pontificado de D. Romualdo Mon y Velarde, años 1804-1805, fol.47.

25 Ibidem, fols. 111-112.

26 GuTIÉRREZ BuENO, P. (1803), Descripción y uso del aparato permanente para desinficionar el aire descubierto por el sabio chímico de París Mr. Guiton de Morveau, Madrid. Esta receta de Morveau contra los miasmas y exhalaciones pútridas, expresada en términos de la nueva nomenclatura, ya había sido traducida por el miembro de la Sociedad Bascongada, Valentín de Foronda (1751-1822). En 1790, Luís García de la Huerta hizo en Segovia un extracto de aquel opúsculo.

27 Una opinión popular era que las grandes fogatas y los cañonazos eran poderosos recursos para desinfectar la atmósfera, buscando la agitación del aire. 
milla, aquella siempre renacerá ${ }^{28}$. Hasta entonces muchas de las prácticas fumigatorias trataban de aromatizar la atmósfera viciada ${ }^{29}$, es cierto que el ambiente era más agradable, pero el mal, de existir, continuaba: «Los Nervios del olfato perciben una sensacion diferente, no hay duda; pero el mal queda en toda su fuerza, y ahora en la misma actividad. Es lo mismo que si en un vaso de Veneno se echase azucar, el gusto seria diferente, pero el efecto el mismo ${ }^{30}$. El verdadero desinfectante debía tener la propiedad de destruir los elementos extraños que hacían nociva la atmósfera, y no conformarse con enmascarar los olores o difuminarlos.

El plantamiento difundido por el arzobispado irá tomando fuerza con los años $^{31}$. Por ejemplo, cuando Antonio Martí y Franqués analizó la composición atmosférica sobre las balsas de enriar el cáñamo no reparó en el fuerte olor que generaban las fermentaciones producidas, él se limitó a demostrar que no había pruebas de alteraciones en la proporción de los gases atmosféri$\cos ^{32}$. En esta línea olfativa los textos recogen indicaciones comparativas: el

28 AHAT. Pontificado de D. Romualdo Mon y Velarde, años 1804-1805, fol. 111.

29 En base a esta creencia, para mucha gente, perfumarse sustituía a la práctica de lavarse. Hasta comienzos del siglo XIX operó una concepción de la limpieza por la que esta se centraba sobre la ropa, que había de cambiarse cada cierto tiempo, pero no se decía nada sobre el aseo del cuerpo. Tanto para los cuerpos como para los locales el perfume y la ventilación purificaban; esta especie de «medicina de los olores» tenía su imagen en las prácticas hospitalarias cotidianas.

30 AHAT. Pontificado de D. Romualdo Mon y Velarde, años 1804-1805, fol. 111.

31 Los tratados sobre higiene siguen considerando, durante el siglo XIX, que las emanaciones pútridas eran nocivas para la salud, y exponen multitud de anécdotas para avalar esta opinión. Lo cierto es que no se hallaban hechos que probaran el origen de una epidemia en las emanaciones pútridas; incluso los efluvios de letrinas y pozos fétidos no producían efecto inhalados al aire libre. En 1858 el Támesis tenía un deplorable estado y, a pesar de los malos olores, no se dio ninguna epidemia, esto ayudó a que la Asociación Británica para el progreso de las Ciencias sostuviera las siguientes proposiciones: « $1^{\text {a }}$ que el aire atmosférico, por solo contener olores de diversa naturaleza, no es necesariamente perjudicial a la salud; $2^{\mathrm{a}}$ que frecuentemente es más nocivo el aire desprovisto de olores; $3^{\mathrm{a}}$ que los olores, como tales, no perjudican, ni aun á los que los respiran habitualmente; $4^{\mathrm{a}}$ que los gases deletéreos que se desprenden con los efluvios son los únicos dañinos, cuando son absorbidos y acarreados al torrente circulatorio, á causa de tener el aire menor presion; $5^{\text {a }}$ que las emanaciones de las alcantarillas, sometidas á una rápida corriente, no tienen nada de pernicioso; $6^{\mathrm{a}}$ que no está probado que la calentura tifoidea tenga su origen en la fermentacion del agua de las alcantarillas; $7^{\mathrm{a}}$ que el perfeccionamiento de los sistemas de alcantarillado no dará por resultado la disminucion de las enfermedades». Citado en GINÉ, J. (1882), t. II, p. 173.

32 Aspecto defendido en su memoria Sobre la cantidad de aire vital que se halla en el aire atmosférico y sobre varios métodos de conocerla, leida en la Real Academia de Ciencias Naturales y Artes de Barcelona el 12 de mayo de 1790. 
mefitismo de las fiebres intermitentes se parecía al olor de los ratones, el de las viruelas al pan cocido y el de la fiebre puerperal tenía carácter ácido; sin embargo, las calenturas malignas no se asociaban con ningún olor. Había lugares donde las emanaciones pútridas eran evidentes: salas de disección, mataderos, cementerios, letrinas, cloacas, estercoleros... Pero no todos los higienistas creían que dichas emanaciones, aunque desagradables, fueran nocivas, a excepción de los gases tóxicos o de las que producían contagio. $\mathrm{Cu}-$ riosamente, según creencia muy antigua, había quien pensaba que las emanaciones pútridas eran un recurso profiláctico contra las pestes

Como desinfectante Guyton de Morveau aconsejaba las fumigaciones de ácido muriático ${ }^{33}$ (clorhídrico), conocidas como fumigaciones clóricas o guytonianas, cuya presencia en los tratados sobre desinfección fue muy durade$\mathrm{ra}^{34}$. Los vapores se producían haciendo reaccionar aceite de vitriolo (ácido sulfúrico) con sal caliente ${ }^{35}$, y su efecto se explicaba porque el ácido muriático neutralizaba y destruía los miasmas pútridos. Desde el arzobispado tarraconense, los párrocos fueron instruidos para aplicar los reactivos en las proporciones adecuadas según el tipo de estancias. También la ropa de los enfermos se exponía a las fumigaciones, y se siguió aconsejando el uso del vinagre: «Es muy conveniente tambien que los Confesores y asistentes lleven consigo un frasquito de vinagre radical, que es un antiputrido poderoso, aplicándole á las narices de quando en quando, ya sea inmediatamente, ya sea echando unas gotas en el pañuelo» ${ }^{36}$. El vinagre era valorado uno de los agentes más poderosos para evitar el contagio de las fiebres pútridas, los médicos respiraban a través de un tampón impregnado y los monarcas europeos hacían gran acopio de él para proveer a sus súbditos ${ }^{37}$. La desinfección del aire de las estancias se realizaba hirviendo vinagre en un recipiente hasta que se desprendían los vapores acéticos.

33 Del latín muria (salmuera).

34 Estas fumigaciones rindieron un inmenso servicio a la salud pública mediante la desinfección de las salas de los hospitales y las celdas de las prisiones. Guyton de Morveau (17371816) realizó en 1773 un descubrimiento importante: el de las propiedades desinfectantes del ácido muriático y más tarde del cloro. Este miembro de la Academia de Dijon partía de una teoría falsa sobre la difusión de los miasmas, creía que las emanaciones de álcali volátil (amoníaco) los arrastraban fuera de la materia orgánica en descomposición; al destruir el amoníaco pensaba que desaparecían los miasmas y con esta finalidad utilizó un ácido gaseoso y fuerte.

35 La reacción fue descubierta por Glauber: $2 \mathrm{NaCl}+\mathrm{H}_{2} \mathrm{SO}_{4} \rightarrow \mathrm{Na}_{2} \mathrm{SO}_{4}+2 \mathrm{HCl}$

36 AHAT, fol. 112.

37 Gazeta de Barcelona, no 14, 16 de febrero de 1779, p. 109. 
A finales del siglo XVIII se popularizaron remedios derivados de la quina para curar las fiebres intermitentes. En Cataluña, ante las epidemias producidas en el Urgel, y con el encargo del rey para atajarlas, el médico José Masdevall ${ }^{38}$ diseñó una bebida para su pronta curación, que el propio facultativo llevó, en 1785, a las tierras vecinas de Aragón para poner remedio a las fiebres que, desde principios de 1784, las afligían: «Así como el Sr. Masdevall no es un empírico, su remedio no es un secreto; este se reduce en sustancia á una simple bebida antipútrida compuesta de tártaro emético, de sal amoniaco, de ajenjos, y de quina» ${ }^{39}$.

En 1787, el primer director de la Real Sociedad Económica de Tárrega, el conde del Carpio, envió al alcalde mayor de la ciudad, y miembro destacado de la Sociedad, Josef Manuel Picado, dos escritos de Santiago Puig, médico de la Santa Hermandad del Refugio y del Hospital de la Latina, donde se proponía el mejor método para curar las tercianas y cuartanas ${ }^{40}$. En esos escritos se debía aconsejar el uso de la quina, pues es el mismo Picado quien se hace traer de la Real Botica, y a sus expensas «una crecida porción de selecta quina», que mediante recetas de los médicos reparte gratis a los afectados por las fiebres. De todos modos son escasas las referencias al empleo del polvo de los jesuítas en los documentos de la época, lo cual parece indicar un empleo limitado y extraordinario.

Entre los autores que investigaban sobre pneumática hallamos algunos remedios derivados de la química de los gases. Sigaud de la Fond aconsejaba a los enfermos de fiebres pútridas un régimen alimenticio abundante en vegetales ricos en aire fijo (dióxido de carbono) ${ }^{41}$, preconiza el empleo del aire deflogisticado (oxígeno) por los enfermos de fiebres, y, siguiendo las experiencias de Priestley, recomendaba incorporar dióxido de carbono en la bebida como antipirético ${ }^{42}$.

38 MasdeVAlL, J. (1786), Relación de las calenturas pútridas, y malignas, que en estos últimos años se han padecido en el principado de Cataluña, y principalmente de la que se descubrió el año pasado de 1783 en la ciudad de Lérida, llano de Urgel, y otros muchos corregimientos y Partidos, con el método feliz y seguro de curar semejantes enfermedades, Madrid, Imp. Real. ( $2^{\mathrm{a}}$ edición)

39 TORRES AMAT, F. (1836), Memorias para ayudar a formar un diccionario crítico de los escritores catalanes, Barcelona, Imp. de J. Verdaguer, p. 407.

40 Archivo Histórico Comarcal de Tárrega (AHCT). Real Sociedad Económica de Tárrega. «Acta leída en la Junta General de 1787», legajo ${ }^{\circ}$ 1, fol. 145.

41 Alimentos con alto porcentaje de glúcidos.

42 DE LA Fond (1785), pp. 66, 70, 412. 
Excepcionalmente, en la bibliografía técnica se relacionan las fiebres tercianas con la ingestión de ciertos alimentos, por ejemplo el pepino: «Los Egypcios los comen despues de estar muy maduros, pero ignoramos si advertirán en su uso los mismos efectos y peligro de tercianas que nosotros ${ }^{43}$. Hipócrates señalaba la dieta como un factor involucrado en las epidemias. Pero el mundo vegetal fue también remedio contra la infección del aire, como el famoso azafrán de la Mancha ${ }^{44}$. En sus Cartas marruecas José Cadalso recogía ambos extremos, recordaba que comer melones daba tercianas ${ }^{45} \sin$ olvidar el uso que hacía la medicina moderna de la quina para remediarlas ${ }^{46}$.

\section{LOS PROBLEMAS SANITARIOS DEL CULTIVO DEL ARROZ}

El problema sanitario del cultivo del arroz generó una gran polémica en Cataluña. Existían en Cataluña zonas pantanosas naturales como el llano del Llobregat donde el paludismo era endémico. Las zonas templadas mediterráneas eran las más castigadas, pero también la Cataluña interior padeció las epidemias y la agricultura parecía implicada. Para remediarlo, mediante real orden del 25 de enero de 1721, Felipe V prohibía el cultivo del arroz en el Ampurdán. La prohibición pretendía erradicar la enfermedad pero llevó el hambre a las familias humildes. Por ello, el 1 de febrero del siguiente año una representación del marqués de Castel Rodrigo exponía al rey la necesidad imperiosa del cultivo del arroz para la gente pobre y de tropa, así como la inaptitud de aquellas tierras para el desarrollo de otras especies vegetales, y el monarca resolvía suspender la prohibición. La polémica continuó, promoviéndose en 1739 varios recursos para prohibir de nuevo el cultivo del arroz en el Ampurdán que finalmente, por una disposición del doce de abril de 1742, tuvo una aplicación muy restringida considerándose que la siembra del arroz era más beneficiosa que perjudicial para la salud pública. Sin embargo, los estragos del paludismo en años venideros constriñeron las voluntades.

43 Boutelou, C.; Boutelou, E. (1801), Tratado de la huerta o método de cultivar toda clase de hortalizas, Madrid, Imp. de Villalpando, p. 329.

44 En BOWLeS (1782), p. 250.

45 También Joseph Townsend, viajando por la costa mediterránea, considera como causa de las fiebres intermitentes el comer melones y sandías antes que las aguas pantanosas. La descripción de su viaje se halla en Townsend, J. (1791), A Journey through Spain in the years 1786 and 1787, Londres, Ed. Dilly.

46 Cadalso, J. (1988), Cartas marruecas, Madrid, Ediciones Cátedra, carta LXXVIII, pp. 272-273. 
Donde el paludismo se hacía endémico reinaba la desazón, y era opinión general que cultivar arroz multiplicaba las desdichas:

«Hay tales enfermedades que comprehendiendo â casi todos los individuos no pueden asistirse unos â otros; que fallecen muchisimos; que las Mugeres preñadas abortan todas; que traszumandose las aguas arrozales en los pozos, y fuentes, las infectan; que muriendo varias savandijas, y reptiles en los que llaman enxugones, corrompidos a la fuerza del sol inficionan los ayres de suerte que de muy lexos se perciben sus perniciosos vapores; excediendo los años de arroz con tan increible aumento los muertos y enfermos que a continuarse la siembra acabarán las familias y los Pueblos» ${ }^{47}$.

Para los partidarios de esta práctica agrícola las causas de la alta incidencia de enfermedades eran ciertas costumbres, como el alcoholismo; incluso se afirmaba que, por el contrario, el movimiento de las aguas en los arrozales purificaba la atmósfera. Pero la razón de mayor peso era práctica, pues casi todos los arrozales estaban en tierras salinas donde no se podían cultivar otras especies ${ }^{48}$.

La confrontación hizo necesaria la intervención de la Junta de Comercio de Barcelona, dictaminando que la perniciosidad del cultivo provenía de las aguas empantanadas. La solución era dotar los campos de acequias de drenaje para el desagüe de las aguas estancadas. La Junta quiso asegurarse de las medidas a tomar encargando a Francisco de Prats, regidor de Gerona, que estudiara el tema in situ. El resultado fue un informe ${ }^{49}$ presentado al marqués de la Mina que éste remitió a la Real Audiencia. En dicho documento se constataba el carácter pantanoso de la comarca, con cenagales y zanjas que contenían aguas corrompidas, y recogía el carácter partidista que movía a unos y a otros alrededor del cultivo del arroz. Las conclusiones de Prats se plasmaron en la Ordenanza de 1767. Por dicha Ordenanza sabemos que los arrozales del Ampurdán estaban demarcados por mojones de piedra, situados a 250 canas de los pueblos, unos 390 metros. La zona dedicada al cultivo del arroz estaba dividida en cinco partidas y, anualmente, se sembraba sólo una de ellas, si-

47 Archivo Junta de Comercio (AJC), leg. XXVI, caja 37, doc. 1.

48 Ibidem.

49 AJC, leg. XXVI, caja 37, doc. 1. «Informe de lo practicado en la Comisión que trata, para arreglar la siembra de Arrozes, a fin de que su noticia sirva de Instrucción para la que tiene pedida sobre el propio asumpto la Corte». También se refiere a este problema, IGLESIES, J. (1969), Síntesi de la Junta de Comerç de Catalunya (1760-1847), Barcelona, Rafael Dalmau, p. 56. 
guiendo una estricta rotación que se justificaba desde el punto de vista sanitario: «Las demás tierras Arrozales exteriores á los citados mojones se distribuirán en cinco Divisiones, las quales turnarán entre si de suerte, que sola una de ellas se pueda sembrar en cada un año, y en cada quinquenio se verifique haberse executado la siembra en todas: Con cuya providencia no hallandose sembrado el Arroz todos los años, sino en la quinta parte del Territorio, quedarán siempre las otras quatro, y la salud de sus habitantes, libres de aquellas impresiones que les pudieran ocasionar las aguas y plantas Arrozales ${ }^{50}$. Planificación completada con la realización de acequias y zanjas de drenaje. Con esta rotación quinquenal también se buscaba controlar la mala hierba llamada vulgarmente cogula (Avena fatua), gramínea que era muy perniciosa para el agricultor gerundense.

También el fiscal de la Real Audiencia de Barcelona, Manuel Sisternes y Feliu, dictaminó en la controversia ${ }^{51}$. En su opinión las tierras pantanosas deberían dedicarse a la plantación de arroz, pues la experiencia dictaba que si no se sembraban las aguas estancadas se corrompían más fácilmente. Según la concepción de los efluvios pestilentes, el propio cultivo del arroz los disminuía con el movimiento de las aguas. Evitando, mediante el riego, que esas zonas se secaran en verano no había mortalidad de organismos y, por consiguiente, corrupción, origen de las exhalaciones. Pero Sisternes también aconsejaba prohibir el cultivo del arroz en tierras que no fueran de naturaleza pantanosa. Con esta medida se evitaría trasladar a los suelos normales las características indeseables de los pantanos. El arroz se consideró una planta regeneradora para los terrenos pantanosas pero desechable en los demás casos. Una opinión más drástica se hallaba presente entre quienes consideraban el arroz un cultivo dañino para la salud. Cultivar arroz era más perjudicial que dejar el terreno pantanoso con su vegetación autóctona, pues al eliminar malas hierbas el agricultor promovía la putrefacción, foco del mefitismo palúdico.

50 Ordenanza o reglamento general que hasta nueva resolución de S. Magestad o de su Real Consejo se deberá observar para el cultivo de los arroces en los pueblos del Ampurdán, Barcelona, Thomás Piferrer, 1767, p.4.

51 Sisternes, M. (1786), Idea de la ley agraria española, Valencia, Benito Monfort, p. 29. Sisternes que nació en Castellón en 1728 y se doctoró en derecho en la Universidad de Valencia, abandonó Barcelona en 1779, yendo a Madrid promovido al cargo de Alcalde de la Real Casa y Corte. En junio de 1779 es admitido como socio en la Real Sociedad Económica de Madrid. El manuscrito sobre la Idea de la Ley Agraria Española, redactado a principios de 1785, fue leído en la Junta de Agricultura de la Sociedad durante los meses de octubre y noviembre. En su estancia en Cataluña se interesó por la agricultura, como afirma en su libro. 
Como vemos, aún las opiniones más favorables restringían el cultivo del arroz y la agronomía anhelaba hallar una solución. Los rendimientos económicos del arroz eran importantes pero, por su insalubridad, se quería relegar como cultivo marginal. Los labradores interesados en cultivarlo debían pedir permiso a las autoridades municipales, siéndoles a menudo denegadas, cuando no era expresamente prohibido. El cultivo del arroz tiene así una larga historia de tolerancia y prohibición, sobre todo en tierras valencianas donde en 1483 se prohibió bajo pena de muerte para quienes contravinieran el mandato regio. Durante los siglos XVIII y XIX la región valenciana estuvo muy sensibilizada ante los gases mefíticos, debiendo intervenir el monarca reiteradamente ${ }^{52}$. Esta sensibilización frente a los perniciosos efluvios abocó a los valencianos a mantener las calles de la ciudad limpias y, en compensación, consiguieron un abono estimado por los agricultores. La materia orgánica en descomposición acumulada en las calles y cerca de las viviendas era retirada por los agricultores, lográndose con aquella práctica un doble beneficio: fertilizar los campos y alejar la corrupción - origen de enfermedades - del entorno ciudadano. Agricultura e higiene pública se complementaban admirablemente ${ }^{53}$.

La relación entre la salud y enfermedad de las tierras pantanosas fue una constante para los intereses agrícolas valencianos ${ }^{54}$. El cultivo del arroz desataba pasiones encontradas, y cuando un autor exponía su opinión sobre el particular rápidamente merecía las críticas del bando contrario impugnándole. Esto ocurrió con el reputado naturalista Antonio J. Cavanilles, a quien se le criticó por su postura restrictiva expuesta en su conocida obra sobre el reino valenciano ${ }^{55}$, expresando su parecer de que sólo en terrenos pantanosos debía consentirse cultivar arroz, y ni tan siquiera en éstos si estuviesen cercanos a

52 Ramírez, B. A. (1865), Diccionario de Bibliografía Agronómica, Madrid, Rivadeneyra, p. 605 .

53 TORRE, Marqués de la (1788), Discurso sobre lo útil, y aún necesario que se cree ser a los campos de la huerta de esta Ciudad el estiercol y polvo que se saca de sus calles, y perjudicial a la salud pública que permanezca en ellas, Valencia, Oficina de D. Benito Monfort, pp. 49-52.

$54 C f$. CHAIX, E. (1801), «Memoria premiada, que contiene una noticia de las lagunas y terrenos pantanosos de este reino (Valencia), y los medios para su desecación, con reflexiones sobre las ventajas que resultarán a la salud pública, ganados y Agricultura; operaciones prácticas para desaguar las lagunas de Ayora y de Salinas», Junta pública de la Real Sociedad de Valencia, Valencia, Benito Monfort.

55 CAVANILlES, A. J. (1795-1797), Observaciones sobre la historia natural, geografía y agricultura, poblaciones y frutos del reyno de Valencia, Madrid, dos vol., Imprenta Real, (reimpresión de 1958). 
alguna población. No sería la única vez que Cavanilles tratase el tema del arroz. En 1797 presentó en la Real Academia Médica de Madrid la memoria titulada Observaciones sobre el cultivo del arroz en el reino de Valencia ${ }^{56}$, analizando el problema bajo el punto de vista sanitario. Las consecuencias a las que llegó Cavanilles eran: 1. El cultivo del arroz dañaba extraordinariamente la salud pública, por lo que procedía prohibirlo. 2. El arroz consumía cantidades de agua superiores a las empleadas en otros cultivos de huerta, e, incluso, en tierras no pantanosas no resultaba el cultivo más rentable, desaconsejándose para aquellos parajes desde un estricto punto de vista económico. 3 . En las tierras de naturaleza pantanosa, que mejoraban con la circulación del agua, podía darse el cultivo del arroz siempre que se impidiera el crecimiento de plantas adventicias para evitar su corrupción, y de acuerdo con la experiencia local que no probase lo contrario. 4. Demostrado que el cultivo del arroz dañaba la salud, no se debía autorizar esta práctica cerca de los pueblos, aunque las tierras fueran pantanosas ${ }^{57}$.

El principio defendido por Sisternes sobre la bondad del cultivo de arroz para mejorar la salubridad de las zonas pantanosas al provocar la circulación del agua seguía siendo válido, y lo sería transcurrido un siglo. Una real orden de 1860 establecía que las autorizaciones para este cultivo se expedirían sólo para los terrenos de naturaleza pantanosa, que no podían producir otras cosechas y donde el estancamiento de las aguas ocasionara daños a la salud públi$\mathrm{ca}^{58}$. Pero ni la ley, pues hubo constantes denuncias por cultivarlo en tierras no pantanosas, ni las víctimas del paludismo vinculadas a su cultivo frenaron su expansión en Valencia ${ }^{59}$.

Hubo defensores del cultivo clásico del arroz que no hallaron perjuicio sanitario alguno en esta práctica, como el presbítero Simón Buforu que en el tránsito secular dirige al Rey sendos escritos reclamando el beneficio y necesidad de los arrozales: Discurso sobre la necesidad de la siembra del arroz, y sobre que ésta no es perjudicial a la salud pública; y Fundamentos sólidos relativos a la necesidad de la cosecha del arroz, no ser ésta perjudicial a la

56 CAvanilles, A. J. (1797), «Observaciones sobre el cultivo del arroz en el reino de Valencia», Memorias de la Real Academia médica de Madrid, t.I, Madrid, pp.99-128. También existe un Suplemento a las observaciones sobre el cultivo del arroz en el reino de Valencia, Madrid, 1798. Según cita de M. Colmeiro (1858) en La Botánica y los Botánicos de la península Hispano-Lusitana, p. 82.

57 Ibidem, pp. 99-128..

58 RAmíreZ, B. A. (1865), p. 272.

59 Véase «Noticia de la albufera de Valencia y campos de arroz», Memorial literario, t. VII, 1808, p.82. En este artículo también se expone el fracaso del arroz de secano en Valencia. 
salud pública y deberse proveer de remedio absoluto su ejecución para poner fin a los perjuicios causados a los pueblos contenidos en las dos riberas del reino de Valencia, llamadas alta y baja ${ }^{60}$. Pero el cultivo del arroz no logró deshacerse de su mala fama ${ }^{61}$.

\section{El CULTIVO DEL ARROZ DE SECANO}

Anteriormente hemos analizado la teoría miasmática y repasado los remedios aplicados para combatir el paludismo, y la ineficacia de los remedios llevaron a un intento agronómico casi desesperado. Un principio importante de la agricultura ilustrada era no dejar ociosa la tierra, sin importar los factores limitantes pues, aplicando un peligroso criterio de suficiencia, se pensaba que siempre se hallarían cultivos o técnicas adecuadas para el caso. La respuesta agronómica a la polémica sanitaria de los arrozales fue el, equívocamente, denominado arroz de secano. Realmente era un cultivo de regadío, y la denominación de «arroz en seco» que mereció corresponde al cultivo sin riego, dependiente sólo del agua de lluvia. Como las experiencias europeas con el cultivo sin riego fracasaron, se adecuó la denominación de arroz de secano para el cultivo con riegos periódicos. La diferencia con el cultivo clásico era significativa, se realizaban riegos regulares que evitaban el estancamiento y suponía un ahorro significativo y menor dependencia del agua. El objetivo era sanitario: evitar las hipotéticas emanaciones nocivas, causa de las fiebres intermitentes derivadas de las zonas pantanosas.

En Valencia, Josef Antonio Valcárcel publicaba en 1768 una Instrucción para el cultivo del arroz, al modo de otros granos, con riego a días determinados y sin riego artificial. Era una ampliación de lo tratado en el tercer tomo de su Agricultura general ${ }^{62}$, dedicado al cultivo de granos, legumbres, raíces

60 Estos y otros documentos sobre las ventajas y perjuicios del cultivo del arroz en Valencia, se hallaban en el Archivo del ministerio de Fomento, legajo $\mathrm{n}^{\circ} 4$ de Agricultura, años 1785 a 1804, y son citados por RAMíREZ (1865), p.792 y p.817.

61 Un ejemplo lo tenemos en el informe redactado en 1787 por el duque de Crillón y Mahón, enviado al Consejo: Informe y otros documentos sobre los perjuicios de la siembra abusiva de los arroces en la provincia de Valencia.

62 La obra constaba de diez tomos en $4^{\circ}$, de 400 a 500 páginas aproximadamente, su publicación se realizó en Valencia desde 1765 a 1795. Para su redacción, Valcárcel se basó en El noble agricultor del francés Dupuy Damportes, traducción del Cuerpo completo de agricultu$r a$ del inglés Hall. El agrónomo español dejó de banda, conscientemente, la obra tradicional de Alonso de Herrera por su constante referencia a las fases lunares. 
y plantas forrajeras. Algunos años antes, en 1765, y con una finalidad sanitaria, en Valencia se habían iniciado ensayos para cultivar el arroz sin riego continuo. Nuevamente se pedía permiso al Rey para proseguir estas experiencias y Valcárcel solicitaba al Conde de Aranda que, en vista de los esperanzadores resultados obtenidos, los ensayos se extendiesen a otras partes de España:

«Como el Arroz compone en Agricultura un parrafo mui importante por su gran provecho; siendo uno de los mas saludables alimentos, y de los singulares en ser un gustoso suplemento de varios manjares para multitud de gentes; por eso se hace acreedor à que en todas las Provincias de nuestra Peninsula se plantifique su cultivo, de ninguna suerte dañoso en esta forma à la salud publica: porque en todas, ò en casi todas ellas hai territorios, que gozan de riego, ò con facilidad se les podrá dar à corta costa: beneficio que aseguraria lo que tantos cuidados trae en su escasez; y asimismo habrá otros terrenos propios en secano, donde sin duda se criaria mui bueno, y mas sabroso» ${ }^{63}$.

A partir de los ensayos realizados en Valencia debían promoverse otros, como así fue, para comprobar la viabilidad de aquel sistema de cultivo en diversas regiones españolas. Las experiencias presentadas por Valcárcel eran positivas desde el punto de vista sanitario y económico, pues, en su estudio comparado, el arroz de secano rendía más que el cultivado según el método tradicional y era más rentable que otros cultivos como maíz y alubias ${ }^{64}$. El agrónomo valenciano dio por sentada la viabilidad técnica del arroz de secano y no duda de sus efectos positivos para la salud atendiendo a la teoría de los miasmas, rechazando la idea de que la malignidad recayese en la propia planta de arroz.

Pero el arroz de secano tenía problemas agronómicos. Manuel Sisternes, conocedor de la agricultura valenciana y catalana, en el texto del año 1786 daba por zanjada esta tentativa y consideraba un fracaso todo cultivo de arroz que no dispusiera de agua permanente. Sus argumentos se basaban en los ensayos realizados en Valencia a instancias del Conde de Aranda siendo presidente del Consejo de Castilla ${ }^{65}$. No era de la misma opinión el articulista del Semanario de Agricultura y Artes dirigido a los Párrocos que en 1805 daba noticia de los ensayos con arroz de secano realizados en Puzol:

63 Valcarcel, J. A. (1768), Instrucción para el cultivo del arroz al modo de otros granos con riego a días determinados, y sin riego artificial en secano, Valencia, Fco. Burguete, pp. 2-3.

64 Ibidem, pp. 38-41.

65 SiSTERNES (1786), pp. 31-32. 
«Observacion 1 ${ }^{\mathrm{a}}$ : En el Jardin Botánico de Puzol que erigió el Excelentísimo Señor Don Francisco Fabian y Fuero, el que conserva nuestro dignísimo Prelado el Excelentísimo señor Fr. D. Joaquin Company, se cultiva mas hace de 20 años una variedad ó sea especie de arroz extrangero á riegos, y el que fructifica con fuerza y lozanía, en términos de haberle contado á una panoja mas de 400 granos. Observacion $2^{\text {a: }}$ El arroz forastero criado con agua continua y fresca, rinde casi un tercio mas que el del pais, y no lleva arista su corola criado á riegos, y sí cuando se cultiva con agua continua» ${ }^{66}$.

En Cataluña la primera experiencia que conocemos fue realizada el año 1778 por Josef Lomaña, tesorero y miembro de la comisión de agricultura de la Real Sociedad Económica de Amigos del País de Tárrega. Las actas de la Sociedad no recogen ninguna justificación de este proyecto, lo cierto es que detrás no hay ningún premio promovido por la Sociedad. La zona no era pródiga en tierras pantanosas y el problema era más bien la escasez de agua, se trataría, pues, de maximizar los escasos recursos hídricos buscando la alta rentabilidad del arroz mediante el cultivo de secano ${ }^{67}$; o, quizás, existió sólo una motivación personal derivada de los escritos que llegaban a la Sociedad alentando a sus miembros a realizar experiencias en favor del progreso de la agricultura. No muy lejos de Tárrega, en la ribera del río Segre, se cultivaba el arroz mediante inundación continua y, unos años después de la experiencia que comentamos, sobre todo en 1785, una desastrosa epidemia palúdica afectó al Urgel. Varios pueblos solicitaron a la Real Audiencia la prohibición de cultivar arroz en su circunscripción a causa de la elevada mortalidad que las fiebres causaron en el Ampurdán, y en 1795 el gobierno anunciaba severísimas penas para quienes cultivasen arroz mediante agua permanente.

En Tárrega durante la junta general de la Sociedad de Amigos del País, celebrada el 26 de octubre de 1778, Lomaña presentaba a los socios un manojo del cereal resultado de su novedosa experiencia considerando que el arroz «puede llegar a perfecta sazón, con otra segunda experiencia, en que se en-

66 D.V.A.L. (1805), «Del arroz», Semanario de Agricultura y artes dirigido a los párrocos, t. XVIII, n ${ }^{\circ} 456$, p. 198.

67 La falta de humedad superficial era precisamente causa de frecuentes epidemias palúdicas, ya que las poblaciones del denominado campo del Urgel, que en 1786 contenía 186 poblaciones y 96 términos despoblados, debían recoger y embalsar el agua de lluvia necesaria en grandes balsas. Estas aguas estancadas causaban daños porque frecuentemente se «corrompían», de tal forma que a veces los campos quedaban sin cultivo "por hallarse la mayor parte de los habitadores de dicho campo postrados con calenturas epidémicas» (AHCT, Real Sociedad Económica de Tárrega, legajo 1, fol.109). 
mienden algunas cosas que no se han tenido antes en la primera» ${ }^{68}$. Hubo, pues, voluntad de hacer un seguimiento agronómico, pero la segunda experiencia no consta que se realizase nunca y los documentos muestran que el arroz no llegó a buen puerto en el primer ensayo, seguramente las espigas no llegaron a madurar. El cultivo del arroz de secano también interesó a otras sociedades como la Real Sociedad Económica de los Amigos del País de Zaragoza, que, habiéndolo ensayado con éxito, el año 1781 promovía un premio para la clase de agricultura de $« 40$ pesos al que en el propio año con riegos regulares solamente, como se practica con los demás frutos, ó en suelos húmedos sin riego alguno cogiere de propia cosecha mas cantidad de arroz y de mejor especie, que no baxe de dos cahices; $y$ en caso de igualdad se preferirá la cosecha de secano: la Sociedad ha ensayado este método en el presente año con feliz suceso» ${ }^{69}$.

(El arroz de secano también llegó de Asia). En 1795 la Sociedad Económica valenciana y la Junta de Comercio de Barcelona, que hacía las veces de sociedad económica, recibían desde Madrid el documento manuscrito Noticia de las especies de arroz que se cultivan en los montes de la Provincia de Iloilo de las Islas Filipinas, firmado por Alessandro Malaspina ${ }^{70}$. La Junta de Comercio, al menos, recibió parte de las 104 muestras de arroz descritas en el texto, guardadas en canutillos de caña, y, probablemente, el resto de semillas se enviaron a Valencia ${ }^{71}$.

Auspiciado por el monarca Carlos III, el oficial de la armada española Alessandro Malaspina había dirigido un viaje exploratorio de cinco años de duración por los mares de América, Ásia y Oceanía ${ }^{72}$. En septiembre de 1794 atracaban las corbetas expedicionarias de regreso a España. El propio Malaspina encargó a su amigo José Francisco Vila, lo hacía el 21 de marzo de 1795, que remitiera a la Junta de Comercio de Barcelona varias muestras de arroz

\footnotetext{
68 AHCT, Real Sociedad Económica, legajo 1, fol. 30.

69 En Gazeta de Barcelona, no 11, Martes 6 de Febrero de 1781, Barcelona, p.96.

70 Archivo Junta de Comercio de Barcelona (AJC), legajo XXXIII, caja 46.

71 Sobre este documento sólo hemos hallado una referencia en el Diccionario de bibliografía agronómica (1865), de Braulio Antón Ramírez, afirmando que se hallaba en el archivo de la Sociedad Económica de Valencia.

72 Sobre las ciencias naturales en la expedición Malaspina $c f$. GALERA, A. (1988), La ilustración española y el conocimiento del nuevo mundo. Las ciencias naturales en la expedición Malaspina (1789-1794), Madrid, CSIC. Sobre la copiosa bibliografía generada por el tema malaspiniano $c f$. Saiz, B. (1992), Bibliografia Alejandro malaspina y acerca de la expedición Malaspina y de los marinos y científicos que en ella participaron, Madrid, El Museo Universal.
} 
de Filipinas, donde se cultivaba de manera diferente al sistema clásico de inundación permanente. El sistema era arriesgado pues dependía, exclusivamente, de las precipitaciones, motivo por el cual se le denominaba cosecha aventurera. Para probar las semillas y la metodología foráneas las pruebas debeían de hacerse en tierras de secano sin ningún riego, tal como se lee en la carta de Vila ${ }^{73}$. Pensamos que el documento y las semillas correspondientes se enviaron sólo a Valencia y a Cataluña, principales regiones donde los problemas del paludismo se relacionaban con el cultivo del arroz. En agosto de 1795 la Junta de Comercio encargó los ensayos a Antonio Martí y Franqués que resultaron negativos. El científico catalán escribió a la Junta en agosto de 1796 reportando el informe de su frustrada experiencia:

«Muy Señor mío: en consequencia del encargo que Vmd. en su Carta del 22 de Agosto de 1795 por parte de la Real Junta de Comercio de este Principado se sirvió hacerme acerca el cultivo de las especies de Arroz de Filipinas, remitidas por disposicion del Gobierno: procedi â mis ensayos, luego que lo permitió la estacion; y habiendose continuado por varios sujetos de mi satisfaccion en diferentes Poblaciones, y tierras de distinta Calidad, asi en los llanos como en la montaña, las repetidas pruebas practicadas en todas las muestras, que he recibido, han sido infructuosas; pues que no ha salido planta alguna de un crecido numero de semillas que se han sembrado. Serian seguramente pasadas por ser cogidas desde algunos años, como lo indica el haberse hallado podridas las que se registron debaxo de tierra; y no quedando ya esperanza alguna de lograr el exito que se deseaba, me parece deber dar este aviso á Vmd. paraque se sirva comunicarlo á la Real Junta» ${ }^{74}$.

Iniciado el siglo XIX las perspectivas para el arroz de secano eran buenas si atendemos a las noticias del madrileño Real Jardín Botánico. Su director, Francisco Antonio Zea, ensalzaba los beneficios de un cultivo que eliminaría los perjuicios para la salud derivados del agua estancada y lo extendería por toda la península aclimatándose bien al frío:

«Entre muchas producciones, ya nuevas, ya raras ó preciosas que ha adquirido el Real Jardin Botánico de Madrid en el presente año, se cuenta la del arroz de secano de que seguramente resultarán grandes ventajas á nuestra Agricultura. Por todas partes lo solicitabamos, hasta que por fin conseguimos tres únicos granos que sin embargo de ser cultivados en maceta han producido hermosos y abundante fruto. No nos proponiamos sacar otra ventaja de substituir este arroz, al que se cultiva inundando el terreno, que el evitar el daño mas ó menos grave que siempre causan

\footnotetext{
73 AJC, legajo XXXIII, caja 46.

74 AJC, leg. XXXIII, caja 46.
} 
á la salud las aguas estancadas, y hemos hallado tambien la de ser mas temprano, y acomodarse perfectamente á los climas frios, de suerte, que en toda ó casi toda la península se podrá cultivar. Jamas se habia logrado en el Real Jardin Botánico que el arroz de Valencia llegase siquiera á florecer, y por consiguiente no habia esperanza de que pudiese cultivarse en lo interior de España; pero el de secano ha fructificado tan perfectamente que no dudamos propagarlo dentro de dos años en todas las provincias» ${ }^{75}$.

Pero los buenos augurios no se confirmaron y, transcurrido más de medio siglo, Braulio Ramírez relata el elogioso afán de Zea, y otros agrónomos contemporáneos, por propagar el arroz de secano y el fracaso del intento ${ }^{76}$.

En Cataluña no pasaron desapercibidos los ensayos arroceros realizados dentro y fuera de España, y acrecentaron las experiencias propias. En este contexto se situa Juan Francisco Bahí, director del Jardín Botánico barcelonés, quién en 1815 inauguraba el periódico mensual Memorias de Agricultura y Artes con el artículo titulado «Del cultivo del arroz en España sin alterar la sanidad de los pueblos». Bahí, conocedor de trabajos precedentes dentro y fuera de la Península no perdía la esperanza de que alguna variedad precoz, como el arroz imperial utilizado en el norte de China, pudiera cultivarse a riegos intermitentes simulando las condiciones climáticas asiáticas ${ }^{77}$. Justificaba las ventajas sanitarias del arroz de secano repitiendo anteriores argumentos, el objetivo era evitar las aguas estancadas aplicando riegos periódicos, eliminando así el factor pútrido del proceso. En 1816 realizó los primeros ensayos cuyos resultados no fueron alentadores, pero no faltó el optimismo:

«Hablaré del ensayo del cultivo del arroz con el riego periódico como las plantas de nuestros huertos; $y$ aunque en este ensayo no he sido tan feliz como con los precedentes, tengo ya arroz en flor y fruto, como ven en el Jardín, y sino ha prosperado igualmente, creo conocer ya las causas de esto, y dejando a parte la crudeza del verano,espero poder remediarlas en el año que viene para así adelantar en este cultivo; y no dudando que esto será luego un axioma, el Ampurdán verá en sus campos el gran cultivo del arroz sin perjudicar a la sanidad de los pueblos, lo que fue objeto de mi primer escrito en las memorias de agricultura; y lo mismo podrá

75 ZEA, F. A. (1805), «Noticia de la adquisición del arroz de secano que acaba de hacer nuestra Agricultura», Semanario de Agricultura y Artes dirigido a los Párrocos, t. XVIII, ${ }^{\circ}$ 458, pp. 239-240.

76 RÁMIREZ, B. A. (1865), p. 686.

77 BAHÍ, J. F. (1815), «Del cultivo del arroz en España sin alterar la sanidad de los pueblos», Memorias de Agricultura y Artes, Barcelona, t. I, pp. 1-3. 
practicarse en el Urgel, luego de verificado el gran canal, que con la generosidad del Monarca y zelo de la Junta de Comercio de Cataluña» ${ }^{78}$.

En adelante, este tipo de ensayos no se citarán como tarea del Jardín barcelonés pero, gracias a las noticias referidas en una memoria inédita leída en 1838 en la Real Academia de Ciencias Naturales y Artes de Barcelona, sabemos que este admirable agrónomo, pocos años antes de su fallecimiento, ocurrido en 1841, y retirado de su actividad académica, aún perseveraba en sus ensayos con el arroz de secano ${ }^{79}$.

Los agricultores y las principales entidades catalanas estaban siempre dispuestos a realizar nuevos ensayos, aun valorando los fracasos precedentes. La aclimatación del arroz en seco fue uno de los proyectos agronómicos más duraderos y esforzados de los que tuvieron lugar en Cataluña. Una y otra vez, cuando se tienen noticias de ensayos con el arroz de secano, se generan renovadas tentativas para conseguirlo en Cataluña. Así sucedió en 1831, cuando la Real Junta de Aranceles envió a la Junta de Comercio ${ }^{80}$ el opúsculo redactado por Claudio Boutelou sobre el arroz de secano titulado Ensayos que para la aclimatación y cultivo del arroz nombrado de secano, se han practicado en el Vergel de las Delicias de Sevilla, publicado en la capital hispalense ese mismo año y traducido al catalán como Instrucció per cultivar l'arrós de secà ${ }^{81}$. La Junta decidió hacer los ensayos utilizando la traducción como guía para los agricultores y la de Aranceles aportó las semillas, que en esta ocasión procedían de América ${ }^{82}$. El texto de Boutelou era fruto de las positivas experiencias realizadas, hacia el año 1828, en el Vergel de las Delicias, atribuyendo a un erróneo sistema de cultivo el fracaso que el arroz de secano padecía

78 BAHÍ, J. F. (1816), «Discurso leído a los discípulos de la escuela de Botánica al empezar sus lecciones, en el cual se da noticia de los felices ensayos de agricultura practicados en el Jardín con el cultivo invernal de plantas que dan aceite, y de la curación de una hidropesía universal y muy graduada a beneficio de la preciosa planta la digital purpúrea», Memorias de Agricultura y Artes, Barcelona, t. III, p. 203.

79 Archivo Real Academia de Ciencias Naturales y Artes de Barcelona (ARAC), caja 22, ms. Noticia sobre el arroz de secano. Memoria leída por Alberto Pujol.

80 AJC, leg. LVII, caja 80, doc. 24.

81 No hemos hallado este opúsculo en catalán, pero sí otro en castellano editado en Barcelona, con una extensión de 20 páginas: Boutelou, C. (1836), Instrucción para el cultivo de arroz de monte llamado comunmente de secano, conforme al método practicado en el Vergel de las Delicias de Sevilla, Barcelona, Imp. Ramón M. Indar.

82 AJC, leg. LVII, caja 80, doc. 24. 
en nuestro país ${ }^{83}$. Boutelou aconsejaba sembrar el arroz en mayo o junio, según fueran las tierras más meridionales o más frías, tarea que podía realizarse, incluso, a principios de julio si diese tiempo a granar y madurar antes de la llegada de los fríos y lluvias otoñales. También se aconsejaba realizar una continua escarda de las malas hierbas y repetir los riegos cada seis u ocho días, según las necesidades, calculándose un rendimiento del ciento por uno. En algunas provincias podría sembrarse una segunda cosecha, tras el trigo y la cebada, supuesto un ciclo vegetativo, desde la siembra hasta la recolección, de tres meses, el mismo que en los climas de origen.

El interés que hubo en Cataluña por indagar la viabilidad del arroz de secano como remedio al problema sanitario del paludismo, está reflejado en sendas memorias presentadas en las sesiones académicas de la RAC en el marco de las lecciones de agricultura auspiciadas por su dirección de Botánica y Agricultura. Corresponden a dos memorias leídas en 1838, la que lleva por título «Noticias sobre el arroz de secano», de Alberto Pujol, es inédita; mientras que la correspondiente a José Faura, «Ensayos que sobre el cultivo del arroz llamado impropiamente de secano se han practicado en el llano de Llobregat», se publicó en el Boletín de la Academia de Ciencias Naturales y Artes ${ }^{84}$.

Pujol investigó los libros de óbitos de muchas parroquias del Ampurdán y afirma haberse «llenado de horror al ver el sin número de victimas que lo fueron por haber prevalecido el interes particular á las quejas de los pueblos». Era evidente que el cultivo del arroz con aguas estancadas desde abril, mes de la siembra, hasta primeros de noviembre, cuando se cortaba el suministro de agua, estaba en el origen de la mortandad. Pujol atribuyó el origen de las epidemias a la putrefacción orgánica y al hedor de las aguas estancadas: «Esta union de circunstancias que todas contribuyen á viciar la admosfera, cuya pureza es necesaria á la vida del hombre produjeron las horribles enfermedades del año 1836, cuyos recuerdos llenan de amargura al hombre sensible, cuyos estragos no reparará el Ampurdan en largos años de perfecta salud» ${ }^{85}$. Opinión compartida, unánimemente, por todos los académicos. El objetivo de

83 Boutelou, C. (1831), Ensayos que, para la aclimatación y cultivo del arroz nombrado de secano, se han practicado en el Vergel de las Delicias de esta ciudad, Sevilla, Diario de Comercio, p. 1.

84 FAURA, J. (1841), «Ensayos que sobre el cultivo del arroz llamado impropiamente de secano se han practicado en el llano de Llobregat», Boletín de la Academia de Ciencias Naturales y Artes, no. 10, Barcelona, pp. 157-159.

85 ARAC, caja 22, ms. Noticia sobre el arroz de secano. Memoria leída por el socio D. Alberto Pujol en el 2do. turno de 1838 correspondiente a la Lección de Agricultura de la Academia de Ciencias Naturales y Artes de Barcelona. 
la memoria de Alberto Pujol era «indagar los medios de substituir á una siembra que da la muerte otra que produce y vivifica ${ }^{86}$. A tal efecto, su exposición recoge los éxitos con el cultivo del arroz de secano en la casa del Barón de Segur. Durante los años 1830 y 1831, la Real Junta de Comercio de Cataluña promovió esta práctica pero los ensayos fueron negativos al no aplicarse una metodología adecuada. Posteriormente, la Sociedad Económica de Barcelona repartió semillas con la obligación de notificar los resultados del cultivo, y fueron estos resultados los presentados por Pujol en su memoria como provechoso ejemplo ${ }^{87}$, incluyendo las reglas para cultivar con éxito el arroz de secano. Se aconsejaba sembrar a últimos de mayo, o primeros de junio, y segar a finales de agosto, ya que el ciclo vegetativo duraba unos dos meses y medio; la tierra debía ser de buena calidad, preparada y abonada como la del cáñamo; antes de la siembre el grano debía remojarse durante treinta horas; el mejor método de siembra era a surcos y, mejor aún, a hoyos, enterrando en cada uno ocho o diez granos con estiércol líquido cubierto con tierra; tras la siembra debía darse un riego repetido antes de nacer la planta, si fuese necesario.

Por su parte, la memoria elaborada por José Faura recoge las experiencias realizadas en el llano del Llobregat en el trienio 1836-1839, prestando especial atención a los microclimas de las parcelas. Faura dedujo una menor sensibilidad al frío de las plantas jóvenes, motivo por el cual aconseja anticipar la siembra a finales de abril o primeros de mayo para que el arroz fructificase antes de mediado el mes de septiembre ${ }^{88}$, señalando como principales ventajas de este cultivo:

« $1^{\mathrm{a}}$ La cosecha del arroz en cuestion es la mas lucrativa con referencia á los demas frutos, por la cantidad y calidad de su producto.

$2^{\text {a }} \mathrm{Su}$ cultivo no trae los inconvenientes de perjudicar la salud pública, ni es tan penoso como el del arroz comun ó acuático.

$3^{\text {a }}$ Está exenta esta planta de padecer las enfermedades comunes á los demas cereales, esto es la del añublo y las producidas por el pulgon o gallinsectos, las cuales con mucha frecuencia dejan burladas las mas halagüeñas esperanzas.

$4^{\mathrm{a}}$ No resulta perjudicada su vejetacion por la proximidad o ascenso de las aguas subterráneas, y por lo mismo las tierras bajas, que á buen seguro componen

\section{Ibidem.}

87 Ibidem.

88 FAURA (1841), pp. 157-158. Sobre los ensayos realizados en el llano del Llobregat, expuestos por José Faura, hemos hallado otro documento en el Archivo de la Junta de Comercio que los explica un poco más detalladamente. Véase «Ensayos que sobre el cultivo del arroz llamado de secano se han practicado en el llano de Llobregat», AJC. Leg. LXVIII. Caja 95, doc. 9. 
una tercera parte de esta llanura, y que hasta el presente se han considerado estériles e improductivas, son muy aptas para el mencionado cultivo, lográndose con este mejorar la condicion de aquellas, desvirtuando la perniciosa accion de las sales que las viican, y levantando o anivelando el terreno, con la doble ventaja de quedar abonado con beneficiosos mantillos o capas de tierra vejetal, si para el riego de dicha planta se aprovechan las frecuentes avenidas cargadas de aquella o lodosas, de las cuales se ha observado ser muy ávida» ${ }^{89}$.

Faura concluyó satisfecho de sus investigaciones y todo indica que si hubo fracasos en el cultivo del arroz de secano fueron debidos a las temperaturas bajas en el período de fructificación, y no hay duda que quienes se acercaban al problema sanitario y agronómico generado por el arroz estaban convencidos de su benignidad cultivado con riegos esporádicos ${ }^{90}$.

El arroz de secano dejó de ensayarse en Cataluña, y en España, mediado el siglo XIX. En la RAC, la última noticia hallada al respecto se refiere al ilustre botánico Mariano La Gasca quien, como académico correspondiente que era, el 3 de enero de 1838 remitió varias muestras de arroz de secano y una instrucción para su cultivo, con el objeto de que la Real Academia hiciera los pertinentes ensayos. Y una década más tarde, en la misma institución, el académico Ramón de Casanova volvía a recalcar la importancia del arroz de secano por sus beneficios sanitarios ${ }^{91}$.

\section{CONCLUSIÓN}

A finales el siglo XVIII y durante la primera mitad del XIX, el cultivo del arroz de secano fue la tentativa agronómica que acaparó mayor interés en Cataluña para erradicar las temidas fiebres palúdicas, vinculadas al método clásico de cultivo por inmersión continua. La agronomía buscaba así una solución a las fiebres intermitentes que la medicina no lograba, desarraigar. Las pruebas documentales no dejan duda sobre el carácter sanitario de estos ensayos. Las múltiples experiencias ponen de relieve que la agricultura catalana estaba abierta al método experimental promovido por la agricultura razonada. Desafortunadamente, las pruebas realizadas por instituciones, como la Junta

89 FAURA (1841), p. 159.

90 Ibidem, p. 159.

91 ARAC, caja 23, ms. Juicio crítico del manual de agricultura de D. Alejandro Oliván, leído en la sesión literaria de la Academia de Ciencias Naturales y Artes de Barcelona, de 29 de Mayo de 1850, por el socio D. Ramón de Casanova y de Mir. 
de Comercio de Barcelona y las sociedades económicas, y particulares, como Juan Francisco Bahí, no obtuvieron resultados satisfactorios pero mantuvieron la esperanza de éxito. En éste, como en tantos otros aspectos agronómi$\cos$, los catalanes seguían el camino iniciado por la agricultura valenciana, trazado por José Antonio Valcárcel en su Instrucción para el cultivo del arroz al modo de otros granos con riego a días determinados, y sin riego artificial en secano. A partir de este momento se suceden numerosas experiencias, informes y reales ordenes que, hasta mediados de la centuria decimonónica, implican a la agricultura catalana en esta innovadora tarea. Quehacer definido por una constante: la necesidad de una motivación externa. 